\title{
PROJETO COPIADORA DO CAPS LUIS CERQUEIRA: DO TRABALHO DE REPRODUZIR COISAS Â PRODUÇÃO DE VIDA ${ }^{1}$
}

\author{
PHOTOCOPIER PROJECT BY CAPS LUIS CERQUEIRA: FROM WORK TO \\ REPRODUCE THINKS AS A LIVE PRODUCTION
}

\section{PROYETO COPIADORA DEL CAPS LUIS CERQUEIRA: DESDE EL TRABAJO DE REPRODUCIR LAS COSAS HASTA LA PRODUCCIÓN DE LA VIDA}

\author{
Ana Luisa Aranha e Silva* \\ Rosa Maria Godoy Serpa da Fonseca**
}

Aranha e Silva AL, Fonseca RMGS da. O Projeto Copiadora do CAPS: do trabalho de reproduzir coisas à produção de vida. Rev Esc Enferm USP 2002; 36(4): 358-66.

\section{RESUMO}

A necessidade manifesta de inclusão no processo de produção da vida material através do trabalho, de uma parcela da população usuária de serviço de saúde mental, deu origem a este estudo. Para apreender o significado do trabalho utilizouse o referencial do materialismo histórico e dialético, fundamentado no conceito de reabilitação psicossocial, e o fez através da análise dos discursos dos usuários. O cenário é o Centro de Atenção Psicossocial Prof. Luis Cerqueira (CAPS). Os resultados indicam a compreensão do trabalho como um instrumento que possibilita aos usuários acessar o campo dos direitos sociais.

PALAVRAS -CHAVE: Saúde mental. Enfermagem psiquiátrica. Serviços de saúde mental. Sistemas de apoio psicossocial.

\begin{abstract}
This study was born out of the necessity manifested by a portion of the population which uses the mental health service linked to the process of producion of materialistic life through work. The intention was to comprehend the significance of work using historical and dialectic materialsm as a reference, based upon the concepts of psycosocial reabilitation and was performed through the analysis of discourses of the users. The site is the Prof. Luis Cerqueira Center for Psyco-Social Care (CAPS). The results evidence the comprehension of work as an instrument which enabled the users access to the field of social rights.
\end{abstract}

KEYWORDS: Mental health. Psychiatric nursing. Mental health services. Social support.

\section{RESUMEN}

Este estudio tuve origen en la necesidad manifiesta de inclusión en el proceso de producción de la vida material, a través del trabajo, de parte de la población usuaria de un servicio de salud mental. Para aprehender el significado del trabajo se utilizó el referencial del materialismo histórico y dialéctico, fundamientado en el concepto de rehabilitación psicossocial, a partir de los discursos de los usuarios. El escenario es el Centro de Atención Psicosocial Prof. Luis Cerqueira (CAPS). Los resultados indican la comprensión del trabajo como un instrumento que possibilita a los usuarios acceder al campo de los derechos sociales.

PALABRAS-ClAVE: Salud mental. Enfermería psiquiátrica. Servicios de salud mental. Apoyo social.

\footnotetext{
1 Extraído da Dissertação apresentada ao Programa de Pós-Graduação da Escola de Enfermagem da USP para obtenção de título de Mestre em Enfermagem, em 1997. Area de Concentração Enfermagem em Saúde Coletiva.

* Enfermeira. Professora Assistente do Departamento da Enfermagem Materno-Infantil e Psiquiátrica da Escola de Enfermagem da Universidade de São Paulo. E-mail: anaranha@usp.br

** Enfermeira. Professora Titular do Departamento de Enfermagem em Saúde Coletiva da Escola de Enfermagem da Universidade de São Paulo. E-mail: rmgsfon@usp.br
} 


\section{INTRODUÇÃO}

Quando vou receber alta e vou poder trabalhar? Como faço para o patrão não perceber que me trato com psiquiatra? Por que sou demitido quando tenho uma crise? Por que não consigo fazer como vocês e trabalhar todos os dias?

O profissional que trabalha em saúde mental reconhece nessas perguntas dos usuários, um pedido de normatização, de negação da doença e de um lugar social de pertencimento. O desafio colocado para todos os envolvidos é equacionar uma situação dada: um sujeito doente, com uma situação possível, um sujeito doente que pode trabalhar. A experiência de coordenar o Projeto Copiadora e o processo de discussão sobre trabalho-atividade produtiva durante anos, junto aos usuários, demonstra que um projeto assistencial para essa população deve incluir mecanismos que a instrumentalize para acessar esse mundo estranho e não habitual: o lugar onde se realiza a reprodução material do ser humano, um universo determinado por um modo de produção, um código de convivência, regras e pré-requisitos aos quais não têm acesso, não só, mas também, pela sua condição de doente mental. Tais questões motivaram essa investigação, assim como a proximidade profissional e afetiva com o objeto de estudo, aliada à necessidade do entendimento do cotidiano, de maior e melhor compreensão da prática desenvolvida no Centro de Atenção Psicossocial Prof. Luis da Rocha Cerqueira, da Secretaria de Estado da Saúde de São Paulo.

\section{O MÉTODO E O PERCURSO METODOLÓGICO}

O materialismo histórico e dialético é o referencial teórico-metodológico adotado no estudo. Para a análise do processo de trabalho dos usuários na Copiadora, foi destacado o conceito trabalho e a categoria processo produtivo (1). São dois os elementos constitutivos do processo de produção: os meios de produção - matéria prima ou o objeto de trabalho e os instrumentos de produção utilizados para transformar a matéria prima. O outro elemento - a força de trabalho, $\dot{e}$ o conjunto das faculdades fisicas e espirituais que existem na corporalidade, na personalidade viva do ser humano(2).

O processo de trabalho é determinado pela necessidade de superação de uma condição anterior do ser humano e o produto desse processo é o ser humano ampliado pelos instrumentos de trabalho, aderido de uma destreza que anteriormente não possuía; o ser humano cuja necessidade foi satisfeita não será o mesmo ser humano, mas alguém que pelo menos uma vez foi satisfeito. Da mesma forma, a necessidade que foi satisfeita não será a mesma, mas modificada pelo ato do consumo, portanto, diferenciada e especificada. As necessidades, no ser humano, são históricas porque assentadas e determinadas pelo estágio de desenvolvimento dos meios de produção e, no decorrer da história, elas se alteram e substituem-se, não são acabadas ou imutáveis. As categorias marxistas de necessidade em geral, não são categorias econômicas, mas categorias histórico-filosófico-antropológicas. Neste sentido mais geral, estão compreendidas as necessidades materiais, espirituais, politicas, de vida social, de trabalho. "A satisfação da necessidade material não constitui somente a condição primeira da vida fundamental do ser humano, (assim como) o refinamento dessas necessidades é em si mesmo, um sinal do (seu) 'enriquecimento"'(3)

Para a apreender o significado do trabalho do usuário na Copiadora, o estudo apoiou-se no conceito de reabilitação psicossocial que considera o "conjunto de todas as atividades que tendem à maximização das oportunidades do indivíduo para sua recuperação e para a minimização dos efeitos incapacitantes da cronicidade. Estes objetivos contemplam o manejo ambiental em nivel individual, familiar e comunitário" (4) ou, de outra forma, é uma estratégia global, política e afetiva que engloba todas as áreas das relações sociais do usuário individual e familiar, inclusive e particularmente o que se refere ao seu estatuto jurídico de incapaz. Por tratar-se de uma população que tem a peculiar condição de ser usuária do serviço de saúde mental, neste estudo tomou-se o conceito de doença mental como o fenômeno que localiza o sujeito num universo distinto, contraposto ao sujeito que não experimentou restrição relacional ou vivencial dada por uma determinada condição de morbidez, resultando um comprometimento de sua qualidade de vida, expresso de forma diferenciada, de acordo com a amplitude das perturbações(5).

Com essa compreensão do processo de trabalho, de reabilitação psicossocial e do processo saúde doença, pode-se traçar um paralelo entre os pressupostos do modelo em saúde mental ainda hegemônico no país, aqui denominado tradição psiquiátrica e o modelo que se pretende transformador, aqui chamado clínica ampliada e que é desenvolvido no CAPS.

A tradição, no país, tem sua base ideológica assentada nos princípios eugênicos e profiláticos das duas primeiras décadas do século $\mathrm{XX}$, operando o modelo hospitalocêntrico de assistência, legitimado pela legislação de $1934^{*}$, que tinha como finalidade o seqüestro do sujeito do meio social e sua exclusão dos

* Esta Lei foi revogada pela Lei $n^{2}$ 10.216, de 06 de abril de 2001. 
centros urbanos. Em contraposição, a clínica ampliada sustenta-se nos pressupostos da Reforma Psiquiátrica, inclui a estruturação de uma rede de atenção substitutiva à hospitalocêntrica, a revogação da condição de inimputabilidade e tutelamento contida na lei de 1934*, afirmando a condição de cidadão do usuário do serviço de saúde mental e o desenvolvimento de projetos de reabilitação psicossocial.

\section{CENÁRIO DE ESTUDO}

O cenário de estudo é o Centro de Atenção Psicossocial Prof. Luis da Rocha Cerqueira, o CAPS, inaugurado em 1987, conseqüência da política da Coordenadoria de Saúde Mental da Secretaria da Saúde de São Paulo (gestão Montoro) que alterou a concepção de atendimento, de estruturação da rede pública de assistência à saúde mental, da formação e capacitação de recursos humanos, influenciando de forma substancial os rumos da Reforma Psiquiátrica.

O CAPS* caracteriza-se como um espaço de intervenção e de formação profissional; um lugar de referência de tratamento e sociabilidade para o usuário e familiar de usuário; é uma instituição aberta e dispõe de instâncias coletivas para discutir e encaminhar as atividades que se inter-relacionam. Na Copiadora, o lugar onde o usuário-trabalhador realiza a atividade produtiva que é o objeto de estudo desta investigação, as atividades iniciaram-se em agosto de 1990 revelando alguns aspectos comuns à população usuária do Projeto Trabalho: dificuldade de relacionamento interpessoal; o medo de situações novas; a apreensão com relação à expectativa familiar e de pessoas do seu círculo social e institucional; a dificuldade de concentração e aprendizagem. De 1990 a 1997 os usuários-trabalhadores articularam formas e regras para solucionar dificuldades individuais e de relacionamento entre equipe de trabalho na reunião do setor, junto com a coordenação do Projeto. O Projeto destina para remuneração da equipe de usuáriostrabalhadores, excluídos gastos com manutenção, setenta por cento do faturamento mensal líquido, Os trinta por cento restantes são destinados a um fundo, com o propósito de ampliar $\mathrm{o}$ setor. A relação usuário-trabalhador e coordenação do Projeto considera os limites da contratualidade operativa, não tem preocupação com o aspecto terapêutico, pois o usuário tem seu espaço de tratamento, para onde é encaminhado quando apresenta demanda dessa ordem.

\section{A FONTE DOS DADOS EMPÍRICOS}

Os sujeitos de estudo são quatro dos oito usuáriostrabalhadores que desenvolviam atividade na Copiadora à época da coleta dos dados, de dezembro de 1995 a janeiro de 1996. 0 procedimento para definição dos sujeitos seguiu o cronograma: uma reunião para exposição do Projeto de Investigação e formalização do convite aos oito usuários-trabalhadores que formavam a equipe de trabalho; na semana seguinte, quatro dispuseram-se a participar do estudo e quatro recusaram-se; foram realizados quatro encontros semanais na forma de entrevistas grupais para coleta dos dados (Anexo 1), uma sessão para a coleta dos dados individuais, respondido individualmente, por escrito, para caracterização da história psiquiátrica (Anexo 2).

\section{OS INSTRUMENTOS, O MÉTODO DE COLETA E ANÁLISE DOS DADOS EMPÍRICOS.}

A escolha recaiu sobre a entrevista semiestruturada porque esta pode oferecer dados que "se referem diretamente ao indivíduo entrevistado, isto é, suas atitudes, valores e opiniões"(6). Os entrevistados receberam como identificação letras alfabéticas, caracterizadas por A, B, C e D, como forma de preservar o sigilo contratado entre a pesquisadora e os entrevistados. Após serem transcritas, as entrevistas foram submetidas à técnica de Análise do Discurso, segundo a orientação de Fiorin (7), de onde foram extraídas as frases temáticas. Uma vez reordenadas em grupos temáticos, deram origem às seis categorias empíricas descritas nos resultados a seguir.

\section{RESULTADOS E DISCUSSÃO}

\section{a) Os sujeitos do estudo}

Participaram deste estudo quatro usuáriostrabalhadores do Projeto Copiadora do CAPS, todos do sexo masculino, nascidos na cidade de São Paulo, solteiros, brasileiros. B, C e D utilizaram os serviços de internação hospitalar, em instituição pública, porém todos têm história de freqüentar um equipamento de saúde mental de orientação substitutiva ao modelo hospitalocêntrico antes da adesão ao Projeto Trabalho. Um deles (C) faz psieoterapia em consultório particular. D foi internado em hospital psiquiátrico após adesão ao Projeto. Dos quatro usuários, C e $\mathbf{D}$ estiveram no mercado formal de trabalho antes da manifestação da doença, enquanto $\mathbf{A}$ e B não.

\footnotetext{
* Em 29/10/1996 foi celebrado o Projeto de Integração Docente Assistencial (PIDA), um convênio entre a Secretaria de Estado de Saúde e a Universidade de São Paulo, que envolve o Centro de Atenção Psicossocial e o Ambulatório de Saúde Mental Centro e os Departamentos de Medicina Preventiva, da Faculdade de Medicina; de Enfermagem Materno-Infantil e Psiquiátrica da Escola de Enfermagem e o Curso de Terapia Ocupacional.
} 
A nasceu em 22/07/1960. Estudou até o primeiro grau e nunca foi internado em hospital psiquiátrico. Indica o início dos sintomas em 1967, a passagem por médicos, um processo de investigação da doença que não "resultaram em nada" e o início do uso de medicamento, que o ajudou a "clarear as coisas". Fez tratamento no Ambulatório de Saúde Mental Centro da Secretaria de Estado de Saúde de onde foi encaminhado, em 1991, para o Projeto Trabalho por um Terapeuta Ocupacional. Faz uso de neuroléptico, benzodiazepínico e antiparkinsoniano.

B nasceu em 31/10/1964, estudou até a sexta série do primeiro grau e diz que a primeira crise ocorreu aos dezoito anos de idade. Para ele, "a doença é uma coisa que acontece com você, na sua infância, na sua adolescência? [...J falta de amigos, uma coisa que aconteceu profundamente. É uma coisa que acontece na nossa vida, no nosso dia a dia. Ela não tem nada a ver com genético, que o médico fala, é uma doença que acontece, por exemplo, fantasia". No curso de uma crise fica "tremendo das mãos, com a cabeça cheia e quente e nervoso" e durante esses anos teve "várias crises algumas pesadas e outras leves ". Faz uso de medicação neuroléptica e foi internado em hospital psiquiátrico duas vezes (a última em 1984). Está desde 1990 na Copiadora.

C nasceu em 02/05/1951, estudou até o segundo grau, esteve no mercado de trabalho por cerca de dez anos e é aposentado. Considera-se "um indivíduo solitário, às vezes eu me isolo das pessoas, mas não é por maldade, é porque é meu jeito de ser [...] O problema apresentou na adolescência, ninguém de minha família sabia [...J quem descobriu que tinha o próprio problema acho que foi eu mesmo, esquizofrenia. Eu gosto muito de ler, onde encontro um pouco de paz e sempre me dá conhecimento mas, também, faz eu me tornar mais sociável. Eu sou de uma familia humilde. Bem pobre. Eu gosto de amizade com mulher que são mais sensiveis, percebem mais o lado carente da gente. Localiza 1973 como o ano que começou a ter "depressões, dificuldade de relacionamento na família e com estranhos" mas não explicita que tipo de experiência obteve do processo de adoecimento. Identifica sua crise com "depressão, isolamento, medo, angústia". Esteve internado em hospital psiquiátrico cinco vezes e a última internação ocorreu em 1991. Foi encaminhado ao Projeto "há pelo menos quatorze meses", por uma psicóloga que o atende em psicoterapia em consultório particular. Faz uso de medicação neuroléptica.

D nasceu em 12/12/1971. Esteve no mercado formal de trabalho até a manifestação da doença, aos dezoito anos de idade. "Era estudante do Colegial Técnico do Curso de Administração de Empresas. Aî chegou o fim de ano e eu tinha ficado prá recuperação. Aí veio o problema e eu não fiz a recuperação. A doença me pegou desprevenido, eu jamais pensaria que fosse ficar louco, que fosse freqüentar a Saúde Mental. Inclusive, no ano de 1990, 91, minha mãe me levava para um Ambulatório de Saúde Mental do Largo 13 de Maio. As vezes eu chegava lá e olhava aquela placa assim, Saúde Mental, eu falava para mim, o que é isso? O que aconteceu comigo?" Caracteriza sua crise pelo fato de ter "alucinações". Ao ser perguntado sobre que tipo de experiência lhe trouxe esse processo, afirma, laconicamente, que obteve "experiência em psicologia". Foi internado quatro vezes em hospital psiquiátrico, sendo a última vez em 1995. Iniciou suas atividades no Projeto em setembro de 1993, encaminhado por uma psicóloga do Hospital-Dia do Itaim-Bibi, equipamento de Saúde Mental da Prefeitura do Município de São Paulo. Faz uso de medicação neuroléptica e anti-parkinsoniana.

\section{b) Como vivem a vida, as relações familiares e sociais}

Segundo eles, a vida de doente mental sofre restrições de relacionamento humano e de troca de experiências. Dois deles ao relatarem experiência de vida não relacionada ao tratamento, indicam a perda de um lugar social: um de estudante e o outro de trabalhador. O fenômeno que os afastou desses lugares, cristalizou-os junto aos demais no lugar de doente mental. Em casa, a relação familiar é pontuada por uma atitude crítica e de desvalorização da possibilidade de inclusão numa atividade produtiva, confirmada por uma condição de morbidez. A família relaciona o ônus do não trabalho à doença. Parece que enquanto a doença não interfere na capacidade produtiva do sujeito, a família não se envolve, o que pode expressar o desamparo a que permanece exposto até os primeiros sintomas e o subseqüente, relacionado à sua condição de sujeito improdutivo. Acredita que tem mais dificuldades devido ao seu funcionamento incompetente, incapacidade para aprender e dificuldade de concentração. Essa concepção de diferença referida a um padrão de normalidade o faz tecer um julgamento negativo de si mesmo, que o coloca num lugar vulnerável, exposto ao preconceito, à discriminação e a dificuldade de entendimento dessa situação.

\section{c) Como percebem o processo saúde-doença mental}

Quanto à causa da doença, relacionam o aparecimento a algo externo ao indivíduo (fatores econômicos, sociais e de relacionamento) ou de ordem biológica (genética), embora um dos participantes do estudo se recuse a atribuir a doença a uma causa genética, contrariando o saber técnico. O que se percebe é uma concepção de saúde-doença multifatorial aderente à teoria da multicausalidade reinterpretada de acordo com a situação peculiar vivenciada no curso da doença mental e influenciada pelo senso comum. Por outro lado, mesmo estando submetidos a um 
agravo de tal magnitude - que derruba, afeta o cérebro, causa decepção consigo mesmo, torna a pessoa dependente, que inviabiliza a vida social não se colocam numa posição vitimizada e dispõem-se ao tratamento e intervenções complementares como o trabalho, com a expectativa de melhorar a condição de doente mental.

\section{d) A atenção à saúde mental}

As falas dos usuários avaliaram as politicas públicas de saúde como "atrasadas" e tal atraso é atribuído à máquina estatal/governamental, compartilhando também aqui, da visão hegemônica do senso comum de ineficiência ou falência das instituições por "culpa do governo".

Além disso, foi possivel depreender no discurso do usuário que tanto no modelo tradicional como no modelo substitutivo a este, é a prática médica que protagoniza a eficiência e efetividade ou não do modelo adotado. Isto porque, "na sociedade capitalista, o valor social do trabalho médico é diferenciado em relação ao valor das demais práticas sociais da saúde, porque este é o trabalho capaz de restabelecer, em menor tempo e em espaço melhor definido (diagnóstico e tratamento), o equilibrio do corpo individual tornando-o capaz de gerar bens ou serviços, portanto, passivel de ser utilizado e explorado como força de trabalho. Neste sentido, a própria ideologia capitalista reitera que o projeto terapêutico deve ser definido pelo profissional médico e que a atuação dos demais profissionais deve ser subsidiária deste"(8). Revelam posição desfavorável ao modelo hospitalocêntrico ainda hegemônico e ao projeto terapêutico desse modelo, baseado na medicação. $\mathrm{O}$ modelo não hospitalocêntrico foi considerado positivo em relação ao anterior. Por outro lado, o movimento de atualização das leis, da transformação da assistência e da inclusão dos familiares no cenário da Reforma Psiquiátrica, parecem distantes da população usuária que relaciona seu tratamento individual a questões locais e não a uma politica mais ampla.

\section{e) Os modelos de atenção em saúde mental}

No modelo tradicional, o usuário identifica tratamento com internação psiquiátrica e o uso de medicamentos. A produção teórica de uma parcela da comunidade cientifica, mais precisamente os pesquisadores da psiquiatria biológica, vem sustentando a hipótese (desde Esquirol) de que o hospital psiquiátrico é o lugar mais adequado para tratar o doente mental. Utiliza como justificativa o argumento sustentado nas últimas sete décadas no Brasil de que o sujeito doente tem dificuldade para envolver-se no tratamento. Essa avaliação não se aplica aos participantes dessa pesquisa, por sua adesão ao longo desses anos ao Projeto Trabalho e porque não necessitaram desse recurso, com exceção de um que teve um afastamento contratado e retornou às suas atividades no Projeto logo depois da alta hospitalar.

No modelo do CAPS, chama atenção o espaçamento do período entre-crises e a compatibilidade de desenvolvimento da atividade produtiva quando do quadro sintomatológico descompensado. Esse fato pode estar relacionado à premissa do Projeto Trabalho que o desenvolvimento da atividade produtiva está ancorado num projeto terapêutico. A atividade produtiva não é a finalidade do tratamento, mas um instrumento de intervenção, num processo de trabalho cuja finalidade é a qualidade de vida transformada. $\mathrm{O}$ modelo de atendimento que considera o usuário, individual e familiar, portador do direito de escolha, utiliza terapêuticas que não se restringem à internação e medicalização é identificado como um lugar diferenciado, de acesso restrito a uma população de poder aquisitivo maior.

\section{f) A compreensão do trabalho na Copiadora}

Do processo de trabalho, destacam apenas um dos seus elementos - a finalidade, ainda assim de maneira bastante tênue. Na definição de trabalho aparece um conjunto de significados contaminados pela ideologia dominante: forma de ocupar o tempo ocioso (ocupação, lazer); ter algo para fazer (treinamento, exercício, terapia ocupacional); estar envolvido em alguma tarefa que o distancie da doença (terapia); de conquistar um lugar de pertinência social (respeito, dignidade e cidadania) e meio que possibilita ao ser humano reproduzir sua vida material (comer, beber, vestir) e social (lazer, convivência, liberdade).

O caráter terapêutico do trabalho expressa, ao mesmo tempo a tradição psiquiátrica e o senso comum, que reconhece o trabalho como tratamento, terapia, um dispositivo mediador e que distancia o sofrimento do ser humano que é seu portador, que dissocia a experiência mórbida da possibilidade de seu entendimento, Entretanto, deslocado da experiência individual, o trabalho adquire um significado articulado com o mundo e o tempo contemporâneo, aos conceitos da sociedade de classes em que vive, relacionado ao acesso à cidadania, o horizonte perseguido por todos os seres humanos, indistintamente. Desta forma, o sujeito que padece de sofrimento psíquico grave, reiteradamente apartado do mundo dos capazes, demonstra clareza e coerência compativeis com as condições de vida atual. Ao reconhecer o lugar que o trabalho ocupa na estruturação do mundo moderno, desde a transição do modo de produção feudal para o capitalista que o excluiu mais visivelmente do sistema produtivo, busca como ser humano sua condição de cidadão, respeitado e digno. Observa-se uma pendulação entre 
a experiência individual e coletiva que lhes permite a aproximação com o coletivo de uma forma articulada e coerente. Sem suporte psíquico constitutivo ou terapêutico, enveredam por uma saída metafisica, quando a realidade lhes impõe o confronto com o individual. Essa pendulação remete à sua concepção do processo saúde doença, já analisada, onde o agravo a que está submetido tem origem fora dele, embora ocorra profundamente nele.

O processo de produção da vida material, na sua dimensão social, efetiva-se pelo trabalho. O ser humano, ao apropriar-se dos instrumentos de trabalho humaniza a natureza e por ela é transformado. A esse processo, Marx (9) chamou trabalho humano, pois o resultado do seu trabalho está inscrito em sua mente antes de sua concretização e guia todo o seu processo de criação, diferentemente do trabalho animal, que é guiado por necessidades imediatas. O processo produtivo determina o padrão aceitável de fragilidade para o desenvolvimento de uma atividade a partir da necessidade dos meios de produção. Desta forma, a força de trabalho que não corresponde à necessidade dos meios de produção, não é absorvida ou é substituída. Os usuários que estiveram no mercado de trabalho ilustram a dificuldade encontrada socialmente para serem absorvidos e a forma como se estabelecem relações de cooperação na sociedade capitalista, marcada pela competição, preconceito com a diferença, insensibilidade com relação aos limites e dificuldades do outro.

Desta forma, é possivel uma sintese parcial: a) otrabalho ocupa o lugar de tratamento quando o doente não tem alternativa de um projeto terapêutico que lhe dê suporte inclusive para poder trabalhar; b)

otrabalho associa-se ao acesso ao mundo das contratualidades sociais quando o doente se encontra em condições de refletir sobre sua atividade, quando pode desvincular sua experiência individual da coletiva; c) o trabalho formal a que alguns estiveram aderidos não lhes propiciou condições para que pudessem incorporar sua singularidade, que foi vivida como um defeito, como uma limitação excludente. Obviamente, esse julgamento social a que estiveram submetidos é mediado por suas capacidades de inclusão e manutenção na divisão social do trabalho e tem início dentro da dinâmica da família nuclear. A experiência de estar vinculado a um projeto terapêutico que possibilita acessar uma atividade produtiva que lhe dá suporte e sustentação, que considera suas particularidades, os faz rever a auto-imagem. Essa avaliação ainda permanece impregnada de uma concepção curativa e restauradora que tem como pressuposto algo estragado que deve ser consertado, mas indica um deslocamento do trabalho da condição de tratamento para a condição de meio ou forma de acessar algo, o respeito. A medida que essas pessoas vão experimentando um lugar que nunca ocuparam ou que estão afastados por força da doença, tecem afirmações que fazem considerar a devastação que a condição de apartado lhes impõe internamente com relação à auto-estima e nas relações sociais mais amplas.

Outra sintese parcial: a) as dificuldades individuais não contempladas com um suporte terapêutico deslocavam o trabalho para o lugar de tratamento; b) superada essa condição, o trabalho é identificado como o meio e o acesso a um lugar social diferente, de inclusão, que faz um ser humano cidadão; c) se o sujeito experimenta a condição de trabalhador, no mercado formal, identifica as dificuldades impostas pelo modo de produção capitalista hegemônico e considera o trabalho na Copiadora uma alternativa e uma oportunidade de estar desenvolvendo uma atividade produtiva; d) quem não esteve no mercado formal se compara aos outros usuários-trabalhadores e inicia um outro processo de deslocamento, agora não como quem nada tem a compartilhar socialmente, mas do lugar de quem tem um lugar diferente dos outros usuários-trabalhadores. Portanto, esse usuário-trabalhador ocupa um status social que é diferente daquele que ocupava quando não desenvolvia seu trabalho na Copiadora.

Do início do Projeto Trabalho até essa análise ocorreu um acúmulo de vivências individuais e coletivas o que permitiu a esses sujeitos processarem diversos e significativos saltos quantitativos (com vistas a um salto de qualidade) na compreensão do seu processo saúde-doença articulada com o desenvolvimento de uma atividade produtiva, isto porque o projeto de Reabilitação Psicossocial do CAPS opera a partir dos pressupostos que compreendem a intervenção reabilitadora não implicada na transformação do estado de "desabilidade em habilidade", mas numa modificação das políticas de saúde- mental, que envolvam os atores sociais (usuários, familiares de usuários e profissionais) num cenário de contratualidades e pressupõe um modelo de atenção ancorado numa política de saúde comprometida com a superação do modo de assistir pautado no paradigma da adaptação e da normatização.

A categoria "usuário-trabalhador" impulsionou a busca de respostas institucionais para dúvidas relacionadas ao vínculo profissional/usuário. Nesse sentido foi necessário desenvolver habilidades para circular de um cenário onde a relação é estritamente terapêutica para outro, onde a relação assume um caráter terapêutico mas que comporta dúvidas e divergências entre coordenação e o usuáriotrabalhador sobre o andamento dos setores, estabelecendo uma relação de "incontinência" terapêutica relativa, mas de grande valor na perspectiva das relações e dos conflitos humanos. 
Esse vínculo se aplica ao novo usuário: o sujeito que se trata e trabalha, recebe remuneração no final do mês, assina ponto, faz conta, troco, cobra funcionários, incluindo os terapeutas, estabelece critério de atendimento do público, determina um ritmo de trabalho, faz falta quando não trabalha, experimenta novas relações sociais que indicam uma mudança interna e um exercício intenso de enfrentamento de dificuldades e de aprendizagem. Esse mesmo usuário discute seu salário, a organização do setor, tem dúvidas e soluções indicando mudanças externas quando adquirem bens para uso próprio ou de pessoas de seus núcleos familiares, através da apropriação do resultado do seu trabalho como, por exemplo, ter dinheiro na poupança, pagar tratamento psicoterápico, comprar medicamentos, ir ao cinema, etc.

Tais mudanças concretas podem refletir mudanças ocorridas no nivel simbólico. Um dos exemplos mais evidentes na Copiadora é o Livro Ponto. Tornou-se usual e parte da rotina do trabalho, marcam sua presença, o dia e a hora de trabalho. Há que se pontuar as dificuldades que tiveram que ser superadas para isso, considerando tratar-se de pessoas acometidas de um agravo psíquico que lhes limita e impõe restrições na relação com o tempo, com o espaço, com as pessoas e com as coisas. Desde 1990 verificam-se mudanças significativas tanto no conteúdo da mensagem (de um risco para o nome) como na forma da letra (de trêmula para firme) e na orientação temporal (de nada para a indicação precisa da data e hora de trabalho). Ao produzirem o Livro Ponto de forma organizada/estruturada, na verdade, o que podem estar assumindo é sua identidade e condição de sujeitos trabalhadores.

\section{CONSIDERAÇÕES FINAIS: A dialética do trabalho na Copiadora e a reabilitação psicossocial}

O Projeto Copiadora é um instrumento de intervenção utilizado no CAPS a partir da necessidade manifesta da população usuária. $\mathrm{E}$ um dispositivo e recurso teórico-prático do processo de trabalho ancorado no modelo de assistência cuja finalidade é a superação do paradigma hospitalocêntrico, ainda hegemônico, da atenção à saúde mental alinhado aos ideais de prevenção, eugenia e educação dos individuos. Tal modelo, legitimado pela Lei n. 24.559, de 03 de julho de 1934, (revogado pela Lei 10.216, de 06 de abril de 2001) não traduz a condição do cidadão que é usuário do serviço de saúde mental e se beneficia do avanço da medicina e da psicofarmacologia, tem escolaridade e informação compativeis com o próprio desenvolvimento tecnológico do mundo capitalista, que esteve no mercado formal de trabalho até o advento da doença, preserva os conhecimentos adquiridos e, é capaz de operar um equipamento de foto reprodução. Os usuários identificam as políticas de saúde com os problemas de administração local, que sofre mudanças de alinhamento ideológico a cada nova gestão e observa-se que a discussão acerca do estado de direito chega aos usuários, individuais, de forma pouco consistente reservando aos movimentos organizados sua maior expressividade.

Ocorre um afastamento na relação dos usuários do seu núcleo familiar quando este último não tem acesso a um suporte terapêutico, quando experimentam um constrangimento familiar pela falta de compreensão do seu limite como força de trabalho, sendo acusados de vagabundos. Por outro lado, familiares que têm acesso a esse programa, aparecem de forma mobilizada e engajada.

Observa-se um posicionamento favorável do órgão financiador das ações de saúde, porém a magnitude do problema impõe uma distância considerável entre o discurso oficial e o financiamento de estrutura substitutiva ao modelo hospitalocêntrico. Os usuários prisioneiros de um sistema de contenção, de não tratamento, que não estão representados neste estudo, não usufruem seu direito aos serviços de saúde, teoricamente garantido pela Constituição, e nos fundamentos do SUS: universalidade, eqüidade e igualdade de acesso ao tratamento.

Nas últimas décadas, a situação da "classe-quevive-do-trabalho" no contexto mundial, sofre a conseqüência da imposição do neoliberalismo e da reestruturação produtiva da era da acumulação flexível com o surgimento do desemprego em escala mundial. Quanto mais o mundo caminha para uma integração globalizada e competitiva, maiores são as taxas de precarização, exclusão e desemprego. Assim, o usuário do serviço de saúde mental que tem demanda por trabalho, experimenta a exclusão social que se dá, não só, mas também, por sua marginalidade no processo de produção (capitalismo consolidado e o padrão econômico neoliberal de mercado), o que não diferencia substancialmente a condição que experimentou nos primórdios da psiquiatria, quando sua existência doentia o impediu de acessar o sistema de produção, no caso o capitalismo emergente (final do século XVIII). No atual contexto histórico e econômico, o usuário de serviço de saúde mental está incluído num contingente expressivo da população em geral, junto a outras parcelas da população excluída do processo produtivo. A premissa (que aceita as populações parceladas como totalidades parciais da população de total de excluídos do processo de produção) evidencia no caso da saúde mental, que cabe ao poder público (políticas de saúde) em parceria com a sociedade civil organizada (trabalhadores da área, associações de usuários, interessados e agregados) a proposição de políticas de atenção à saúde mental que 
contemplem a necessidade (no sentido marxista) dessa população particular, de inclusão no processo de produzir e consumir bens e que apontem para a melhoria de sua qualidade de vida.

O usuário do serviço de saúde mental, por suas características peculiares (baixo grau de escolaridade, formação profissional precária, inserção preconceituosa no imaginário coletivo, habilidade intelectual restringida pelo uso de psicofármacos, relação familiar permeada pela desconfiança com relação à sua capacidade produtiva, além da condição sócio-econômica dependente), experimenta uma condição desfavorável na competição por um lugar no jogo social. Para ele, o trabalho é o acesso ao lugar onde reside a normalidade do ser humano; o respeito do outro (família, parentes, amigos e vizinhos); a possibilidade de prever e viver o futuro; a produção e reprodução da vida material.

Essa sintese foi obtida nos discursos dos participantes desse estudo que mostram a contundência da ideologia dominante, uma vez que não se encontram no mercado formal de trabalho e identificam em si mesmos a limitação que impede ou dificulta sua inclusão. Entretanto, a dificuldade de acesso ao trabalho inclui causas estruturais e conjunturais. Neste sentido, o discurso dos usuários é ingênuo, carrega e incorpora forte carga de preconceito. O preconceito "é a categoria do pensamento e do comportamento cotidianos" e o que caracteriza a vida cotidiana é o caráter "momentâneo dos efeitos, a natureza efêmera das motivações e a fixação repetitiva do ritmo, a rigidez do modo de vida" (10), Por isso, o pensamento cotidiano caracteriza-se por ser "fixado na experiência, empírico e, ao mesmo tempo, ultrageneralizador". A possibilidade de ruptura do preconceito e o redirecionamento da forma de lidar com o pensamento ultrageneralizador (preconceituoso) que contamina usuários, trabalhadores e população em geral em relação ao doente mental reside na assunção de práticas que reflitam um modo de pensar criativo, em primeiro lugar, questionador das verdades estabelecidas e, em segundo e principalmente, solidário com os que têm dificuldades constitutivas. Solidarizarse é superar a concepção de coletivizar excluindo o individual, isto é, a incorporação das individualidades no projeto coletivo, agora humanizado.

O dispositivo das Cooperativas(11) pode contribuir para isso de diversas formas: garantindo no micro espaço da Copiadora e dos demais setores do Projeto Trabalho, o respeito à disponibilidade e ao ritmo de trabalho do usuário; corrigindo a condição atual de projeto subsidiado e conseqüentemente tutelado pelo Estado; intervindo na avaliação do usuário quando este contrapõe a atividade que desenvolve na Copiadora ao trabalho enquanto reprodução de vida material; permitindo a diferenciação de funções no interior do Projeto, incluindo a alteração do contrato de remuneração. Para ser transformadora, essa prática deve buscar o dispositivo mais adequado, pois parece que o Projeto Trabalho do CAPS vem acumulando uma quantidade já considerável de saber e experiência, garantindo uma série de pequenos e significativos saltos quantitativos. Resta chegar a um efetivo salto de qualidade, a superação da condição de usuários-trabalhadores para a de trabalhadores que são usuários de serviço de saúde mental. Observa-se através da afirmação do usuário-trabalhador que o exercício de uma atividade produtiva, associado a um tratamento, amplia seu potencial de relação intersubjetiva, altera o rigor com que julga sua auto-imagem, interfere e modifica a trama da rede familiar nuclear, além de alterar a qualidade da convivência no seu meio social mais próximo, com parentes e vizinhos. O contexto do trabalho do usuário não seria diferente das instituições tradicionais de assistência à saúde mental se a prática do CAPS não estivesse assentada na perspectiva da Reforma Psiquiátrica. Nesta perspectiva, e por não ter correspondência com os pressupostos teóricos do método positivo, o trabalho do CAPS busca necessariamente novos instrumentos de intervenção que ampliam o potencial de troca e o valor social dos usuários de serviços de saúde mental. E, da mesma forma, não é por acaso que essa reflexão foi realizada por uma enfermeira, pois nessa práxis transformadora, cabe a todos a renomeação e a inscrição de outra marca tanto do lugar de usuário como de trabalhadores em saúde mental no imaginário coletivo. Tecnologia das relações humanas ou clínica ampliada é como tem sido nomeada a complexidade de ações experimentadas no cotidiano do CAPS.

\section{REFERÊNCIAS BIBLIOGRÁFICAS}

(1) Paro VH. Administração escolar: introdução crítica. $3^{\mathrm{a}}$ ed. São Paulo: Cortez, 1988.

(2) Marx K. O capital: crítica da economia política. São Paulo: Nova Cultural, 1988.

(3) Heller A. Teoria de las necessidades en Marx. $2^{4}$ ed. Barcelona: Peninsola, 1986.

(4) Saraceno B, De Luca L, Barquero FM. Problemas metodológicos en la evaluación de un programa de rehabilitación. Rev Asoc Esp Neuropsiq; 1992; (40):3-8.

(5) Foucault M. Doença mental e psicologia. $4^{4}$ ed. Rio de Janeiro: Tempo Brasileiro, 1991.

(6) Minayo MCS. O desafio do conhecimento: pesquisa qualitativa em saúde. $3^{4}$. ed. São Paulo: HUCITEC, 1994.

(7) Fiorin JC. Elementos da análise do discurso. São Paulo: Contexto, 1992. 
(8) Silva ALA; Fonseca RMGS. A questão da interdisciplinaridade. Rev Bras Enferm 1995; 48(3):212-7.

(9) Marx K. O capital: critica da economia política. São Paulo: Nova Cultural, 1988.
(10) Heller A. O cotidiano e a história. $4^{\circ}$ ed. São Paulo: Paz e Terra, 1992.

(11) Tesh W. Cooperativismo de trabalho: alternativa ao desemprego. São Paulo: Central Autônoma de Trabalhadores, 1995. (Estudos e Pesquisas Ipros, 2).

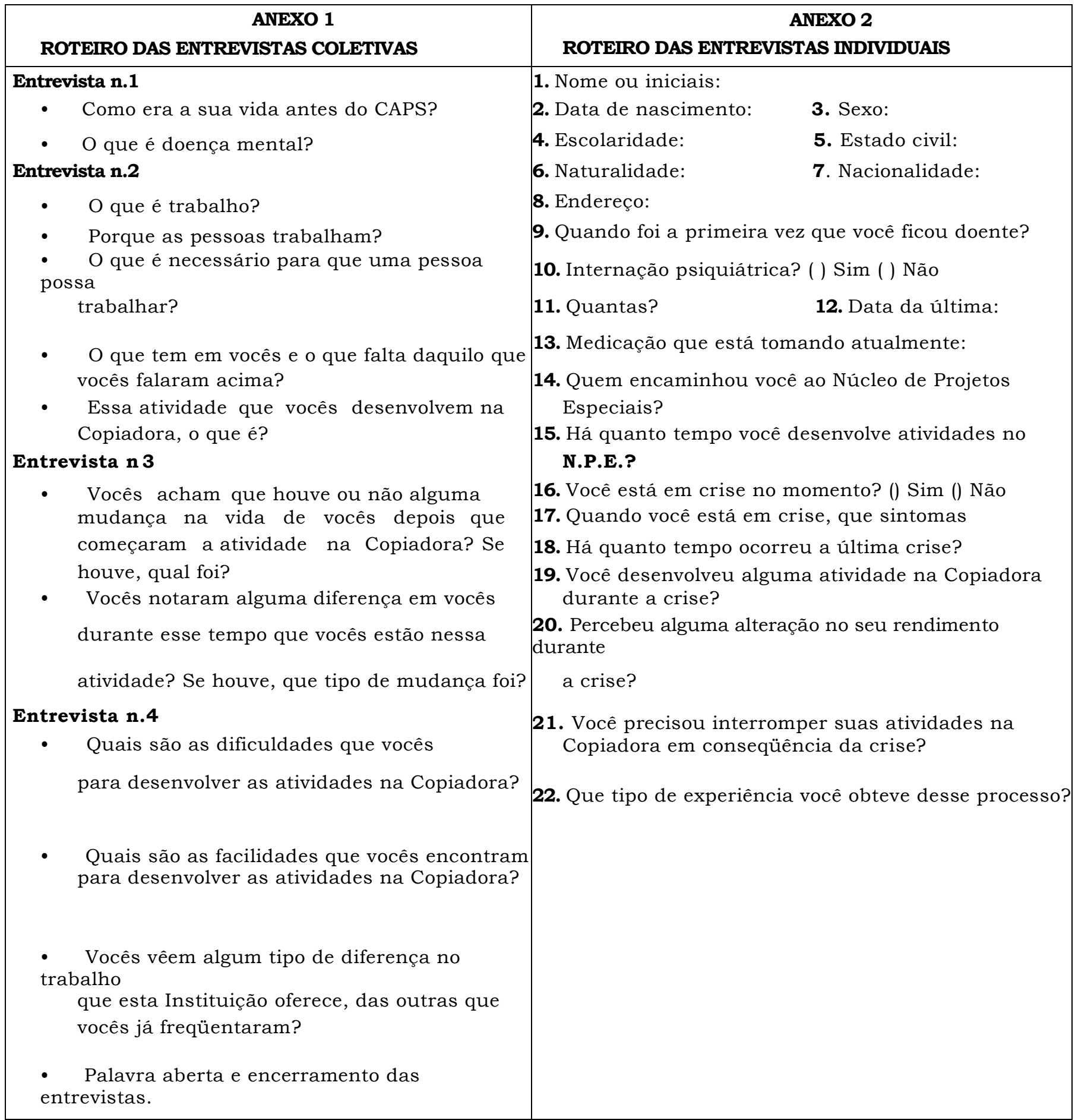

